\title{
CONTENT ANALYSIS PECULIARITIES OF USER INTERNET ACTIVITIES FOR PERSONALITY PSYCHOLOGICAL STATE SLICE FORMATION
}

\section{Lyubomyr Chyrun}

Computer-Aided Design Department, Lviv Polytechnic National University, Lviv, Ukraine

\section{Vasyl Andrunyk}

Information Systems and Networks Department, Lviv Polytechnic National University, Lviv, Ukraine

\section{Victoria Vysotska}

Information Systems and Networks Department, Lviv Polytechnic National University, Lviv, Ukraine

OMESTE

JEL Category: D83, L14, L86

\begin{abstract}
A system for the analysis of the psychological and emotional state of the individual is developed. The aim is to assess the individual through social networks and the practical recommendations. The analysis of assessment data, the problems of this area and the relevance of the system were studied. The diagrams are developed that describe the structure and logic of the system. Description of system requirements according to RUP methodology was done and a prototype application that simulates the activity of individual analysis system was created. In the course of this work, it was carried out creation and development of the information system through which it is possible to conduct a psychological analysis of the individual using his/her Twitter messages. The system helps to automate information gathering project, as well as obtaining and saving the results. It was carried out the analysis of the subject area, as well as considered a variety of information systems based on the certain principle. There was conducted an analysis of the generally known methods and criteria of information systems development. Also, there was also conducted an analysis of the system functionality. There were foreseen the functions that would exist in the system and their usefulness. There was also carried out a

The address of the corresponding author:

Victoria Vysotska

害='victana@bk.ru

systematic analysis of the information system of personality psychological analysis, as well as described the subject area problem and
\end{abstract}


defined project purpose. Using systematic approach basic principles, there were described requirements created by the information system.

Keywords: information resources, commercial content, content analysis, content monitoring, content search

\section{INTRODUCTION}

One of the fundamental principles of modern psychology is a human person dispositional model, which includes 5 relatively independent dispositions (Lovakov, 2013), (Alizar, 2012):

- extraversion/introversion - a person's focus on the external world, talkativeness, sociability, or immersion into the world of imagination and thoughts;

- goodwill - a capacity for mutual help, mutual collaboration, and sympathy towards others

- integrity - discipline, diligence, and resultoriented performance;

- neuroticism - emotional stability degree, impulses and anxiety control level;

- openness to experience - a degree of intellectual curiosity, desire for new and different things, and impressions.

Each person is ranked in order of 5 dispositions this is the way the psychologists make a personal model. It is necessary for the prediction of human action, formulation of conclusions about its suitability, prospects for professional growth, ability to work in a team, possibility of particular individuals to work together for a long time, etc. When hiring a number of organizations, a responsible person should conduct mandatory psychological testing of candidates using each personal model assembly. This is a quite lengthy procedure, which requires certain costs. However, it is possible to significantly reduce the cost of such testing and make it automated. Dr. Shuotian Bai from the Chinese Academy of Sciences has published a scientific paper (Shuotian, Tingshao, \& $\mathrm{Li}, 2012$ ) describing a relatively simple method of calculating each of the five personality dispositions analyzing its activity in social networks. The experienced specialist determines the properties of the human person examining its activity in Facebook or Vkontakte - it is not a big deal for him. Another question is this process automation. In the works (Lovakov, 2013), (Alizar, 2012), (Shuotian, Tingshao, \& Li., 2012), (Solov'yev, 2015), (Dzheffri, 2015), (Prokhorov, 2015), (Kluemper, 2012), (Schwartz, 2013),
(Kosinski, 2013), (Vysotska, 2007-2016) it is explained that each disposition is calculated from the numerical parameters of social network activity. For example, the level of integrity (discipline, diligence, and result orientation) is determined by the number of messages with questions and requests for help. The sign of extraversion is a large number of emoticons; a frequency of status updates shows the openness to experience, and the level of neuroticism is determined by the number of messages that caused a negative assessment of others. Automatic creation of personal models is only beneficial for users of social networks and Web services, as it allows displaying contextual advertising more effective, improve recommendations system, and make dating services better. Perfect knowledge of the audience is crucial for business and recruiting.

\section{ANALYSIS OF THE RECENT SCIENTIFIC PUBLICATIONS}

\subsection{Drawing up a personality model by means of activity in the social network}

When people come to an interview, they "wear" a specially prepared mask. All of them have already rehearsed, but it is a fake. Some companies insist on psychological profiling through evaluation. An understanding of personality and who he/she really is still important for organizations (everyone wants to avoid costly mistakes in hiring, and no one wants to deal with the "destroyers of commands") (Lovakov, 2013). In most cases, in social media, people do not "play" and honestly express their opinion (no one is able to hide their emotions, thoughts, and behaviour for a long time), the analysis of tweets (i.e. Tweet Psych) gives a lot of interesting information (Solov'yev, 2015). Communication is a window into the human mind, and the way a person speaks has much to say about his/her opinions. Linguists have developed two ways of decoding written words into account of human cognitive processes. The first method is Regressive Imagery Dictionary 
(RID). This encoding scheme is designed to measure the amount and type of the three categories of content: initial (unconscious; as they think in a dream), conceptual (logical and rational), and emotional. The second method - Linguistic Inquiry and Word Count (LIWC) - measures cognitive and emotional characteristics of personality on the basis of the words that people use (Lovakov, 2013), (Alizar, 2012), (Shuotian, 2012).

\subsection{Psychological profiles in some famous social networks}

Tweet Psych uses RID and LIWC to create a psychological portrait of a person based on the content of his/her tweets (Dzheffri, 2015). The method is based on comparing the content of user's tweets to the baselines, which are assembled on the basis of the analysis of more than 1.5 million tweets selected at random, and identification of the areas where the user stands out. The service analyzes the last one thousand of tweets (this works best with people who have placed more than 1000 updates). This method is well suited for the analysis of accounts that belong to someone who uses Twitter for conversations, not just as a platform for distributing content. The method measures: fear, oral fixation, work, positive emotions, negative emotions, social behaviour, sadness, spirituality, swearing (offensive language), sexual preferences, dream, sports, education, self-criticism, money, entertainment. In the case of effective carrying out of such studies, many recruiters would use the received data. Nevertheless, there is a huge number of legal nuances in this practice.

LinkedIn: "Pole Position" is in better condition for the establishment of behavioural and psychological profiles (Dzheffri, 2015). Although it is not its main objective, it has an access to analysis of:

- skills/experience,

- working experience (companies where people worked and duration of service),

- career growth (a duration of stay on certain positions),

- teaching and development,

- education,

- future education,

- recommendations,
- groups/associations/members of discussion communities,

- comments made by the members of these groups (possible psychological analysis),

- personal information,

- articles a particular person reads,

- articles a particular person sends,

- profiles a particular person is interested in/has become friends,

- size and the number of connections (network),

- updates made (analyzed for certain data again),

- "liked" places ("Like").

\subsection{Human needs and their behaviour in social networks. "Like" theory}

"Like" is the easiest way to get and give "stroking" on the Internet (Solov'yev, 2015).

1. Need for touching. In psychology, there is a concept of stroking, i.e. actions in which a person directs his/her attention to the partner, and, addressing him/her, indicates that he/she recognizes the presence or him-/herself as a person (Solov'yev, 2015). During this process, the partner feels certain emotions and feelings. This is not necessarily a physical touch (it is a smile, compliment, support, speech, and active listening that emphasize the importance of the human). This is the same need as the need for food, water, air, and heat. Lack of attention makes people emotionally vulnerable and prone to manipulation. A person lacking attention spends huge amounts of energy to meet this need. People get stroking in various ways. Some people become diligent and responsible employees. Others receive it in disputes. Others attract attention carefully watching the appearance. And the fourth receive it by manipulating others.

2. Ways to get stroking: unconditional (obtained by the person for being as is) and conventional (obtained by the person for doing/not doing something) (Solov'yev, 2015).

3. Conditioned stroking reflex. Social networks teach us the principle that "like" can only be earned. In the social network, it is impossible to receive "like" simply for being a human. To get "like" (love, approval, praise, or just to attract attention), one should do something: post funny pictures, write an interesting post, share news, 
change avatars, show new photos, etc. When a particular user posts something, he/she shows that he/she is alive, and we can love and interact with him/her. It is difficult to interact with the users who stay aside the news line. A social network does not allow to "like" the person just because that person is. It is possible to "like" someone's actions or qualities only.

4. Social networks and attitude. People who have harmonious relationships in their family and personal life do not have a dire need of stroking, and their activity in social networks is much lower than those who replace gaps in their personal life by means of social networks. Also, the activity of such people is not aimed at finding acceptance but information and communication. The reasons why people put "like" are as follows.

4.1. "Like" as nonverbal communication. This is a convenient way to show you and express your presence without engaging in conversation. Comments require a response; time is spent on writing the answer. There is no need to waste time and energy on "like". People use "like" to draw attention to them. Sometimes they can not speak out to another person in person, but if they share his/her views, in most cases, they do not mind showing it. They put "like" as an expression of belonging to the thoughts of the post author.

4.2. The tendency to nonverbal communication. On the Internet, verbal language is replaced with a sign language. With information growth, there appeared a need for a new language of communication. People use fewer comments and put more "like". This is a laconic way to express relations. Experts note the trend that people leave fewer comments but use more "reposts" and "like".

4.3. "Like" as a compliment and a way to draw attention. It is also a convenient way to express compliment to a particular person, to attract attention, and the opportunity to meet in person. Social network users usually start familiarity with strangers from "like" (like post), and then they write a message or add to friends. The first compliment, then talk.

\section{4. "Like" button functions}

- social stroking: if its amount is not sufficient in the real world, the user always returns to the network and achieves attention there (it is easier to get it there);
- nonverbal communication;

- information storage;

- news selection for Facebook;

- news promotion within the social network.

5. "Like" problem. This is an approval button, and this verb is an obstacle to some news sharing. Therefore, in its time, Facebook planned to allow its users to create their own verbs for "like" button such as "I am worried about it" or "I am concerned about it" (one may like not all the news, but it is possible to draw public attention to them). They wondered what would happen if use "like" analogue, a button with the formulation of the decision (to understand what this button will make and choose a verb to cause a discord between action and pressing). In social psychology, there is a notion that if a person gave the promise to do something, he/she will make it more likely than if he/she did not give a promise. In "Psychology of Influence" Robert Cialdini wrote that a person most likely performs the action if given a promise than if not given, as people are consistent in their actions and would like to appear so to themselves. For the same reason, there is a button "I will go" on Afisha or Look At Me website. This is an obligation as well. It is also possible to add "help me" button; when clicked, there would drop a list of assistance options. Then all the news pointed out by the user would be in one place by the type of to-do list, where they could be viewed.

\subsection{Social networks: psychology, sociology, and business}

According to the results of various kinds of research, Slavs occupy a leading position in the world in terms of time spent on social networks (Prokhorov, 2015), (Global Web Index, 2009), (Bennett, 2012). In this paper, we will consider the reasons by which users refer to them. We will consider the personal psychological characteristics that determine the pattern of user behaviour in social networks. We will define the ways to analyze user behaviour in social networks and how these data are used for further commercialization of social networks, what opportunities and threats they bring users.

1. Needs for social networks can be defined in illustrations of the researchers from SMTT, where the need for social networks is correlated with Maslow's hierarchy of needs (Fig. 1a) (Prokhorov, 
2015). Set of different human needs can be divided into five main categories. At all levels of social needs, there is a solution offered by social networks. Attribution of one or another social network in one of the layers is conditional. Therefore, Linkedln service got into "Security" layer, as by registering there, one moves primarily by the desire to acquire social capital and make necessary acquaintanceship needed to insure in case of any danger such as job loss, legal issues, etc. Google+ and Facebook got into "Social communication" layer, as these networks provide a possibility to acquire and maintain friendly contacts, family ties, and find a "partner for a serious relationship". Twitter got into "Respect" layer, as for many people it is a convenient way to talk about them, i.e. to raise their prestige in the eyes of others, gain recognition, and talk about the successes achieved. Finally, Blogger, Wordpress, and Tumblr - popular services for blogging - are assigned to "Self-fulfilment" layer. In these services, a user him-/herself is a journalist, poet, and writer; it is a tool for art, spiritual expression, and self-identification.

a)

\begin{tabular}{|c|c|}
\hline Self-fulfilment & $\begin{array}{c}\text { Self-expression } \\
\text { Art - Self- } \\
\text { identification }\end{array}$ \\
\hline Respect & $\begin{array}{c}\text { Self-esteem - Confidence - } \\
\text { Respect from others - } \\
\text { Recognition - Achieving } \\
\text { success and high appreciation } \\
\text { - Career growth }\end{array}$ \\
\hline $\begin{array}{c}\text { Social connections } \\
\text { Security }\end{array}$ & Friendship - Family relationships - Adherence \\
\hline needs
\end{tabular}

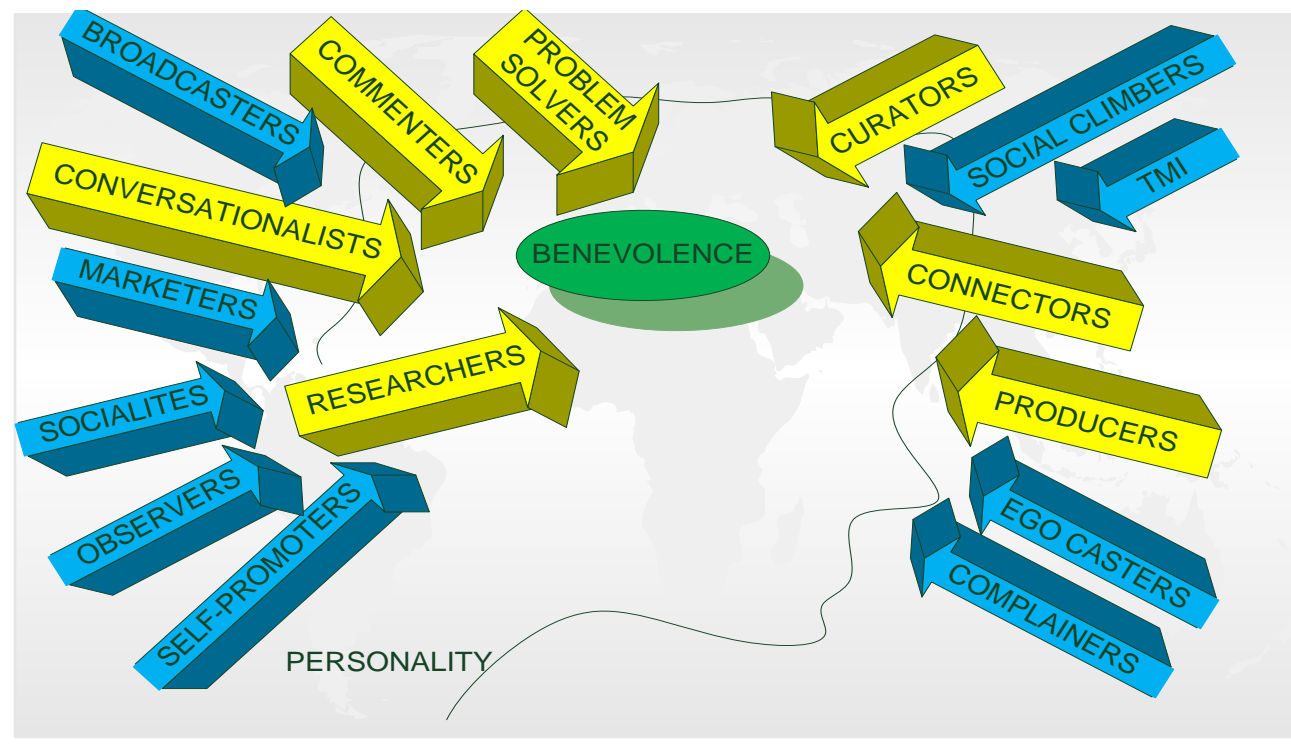

Fig. 1 Maslow's hierarchy of needs (a- source: (Prokhorov, 2015)) and motivation to participate in social media (b-source: (Prokhorov, 2015)) 
Table 1. Categories of users motivated by different purposes of participation in social media (Prokhorov, 2015)

\begin{tabular}{|c|c|}
\hline Name & Explanation \\
\hline $\begin{array}{l}\text { Problem } \\
\text { Solvers }\end{array}$ & $\begin{array}{l}\text { One of the most common sources of debates and social media updates is a } \\
\text { question of people who are looking for information and hope that the network } \\
\text { commentators will tell us how to solve the problem or where to look for solutions. }\end{array}$ \\
\hline Commenters & $\begin{array}{l}\text { The representatives of this category provide their opinions, thoughts, ideas, and } \\
\text { experience on the topic of shared information. In a lesser extent, they are original } \\
\text { authors mostly expressing their opinion based on someone else's content. }\end{array}$ \\
\hline Researchers & $\begin{array}{l}\text { They accumulate information and ideas of the authorities in their community and } \\
\text { actively generate surveys and research in network space. }\end{array}$ \\
\hline Conversationalists & $\begin{array}{l}\text { They participate in discussions, actively update content looking for advice and } \\
\text { comments on it, support themes within the community and between them. }\end{array}$ \\
\hline Curators & $\begin{array}{l}\text { They look for and share information on the relatively narrow topic they are } \\
\text { experts in, filter content, and publish messages that they think professionals } \\
\text { should be interested in. }\end{array}$ \\
\hline Producers & They earn capital reproducing content in different network communities. \\
\hline Broadcasters & In most cases, they distribute content and slightly participate in the discussion. \\
\hline Marketers & $\begin{array}{l}\text { They create an account in social networks for marketing ideas, products, or } \\
\text { services. }\end{array}$ \\
\hline Socialites & $\begin{array}{l}\text { They received recognition/attention in the network transformed in the online } \\
\text { popularity. }\end{array}$ \\
\hline Self-promoters & $\begin{array}{l}\text { They are focused on restoring the content about their own success, events they } \\
\text { took part in, etc. }\end{array}$ \\
\hline Egocasters & $\begin{array}{l}\text { Modified self-promoters. Due to the constant promotion of their persons and } \\
\text { careless attitude towards others, they lose their sense of reality creating the } \\
\text { impression of themselves like people who praise their own point of view, which } \\
\text { often ignores the views and knowledge of the team. }\end{array}$ \\
\hline Observers & $\begin{array}{l}\text { "The silent majority" that reads the content but does not participate in the } \\
\text { discussions and does not give comments. }\end{array}$ \\
\hline Social Climbers & $\begin{array}{l}\text { They behave insincerely and selfishly towards members of social space } \\
\text { publishing posts with a single purpose - to acquire weight in the eyes of the } \\
\text { certain people who can contribute to their career development. }\end{array}$ \\
\hline Spammers & $\begin{array}{l}\text { They get acquainted with everybody feigning an interest in others and desire to } \\
\text { be friends with a single purpose - to create a group to send spam. }\end{array}$ \\
\hline Complainers & $\begin{array}{l}\text { They use dissatisfaction as the main material for their posts, get pleasure from } \\
\text { the issuance of negative emotions in the network space. }\end{array}$ \\
\hline $\begin{array}{l}\text { TMI } \\
\text { (Too much } \\
\text { information) }\end{array}$ & $\begin{array}{l}\text { More and more users in social media publish information that is personal and } \\
\text { private. Therefore, it should not be subject to public discussion. This behaviour } \\
\text { is a kind of social exhibitionism and is negatively assessed by the part of the } \\
\text { network community. }\end{array}$ \\
\hline
\end{tabular}

2. Individual aspects of motivation to existence of commonly reviewed motivations, participate in social media. Despite the there are undoubtedly country-related 
psychological characteristics of the individual (Prokhorov, 2015). This issue is devoted to a number of studies (Lovakov, 2013), (Alizar, 2012), (Shuotian, Bai, 2012), one of which is a graphic illustration of the individual qualities that attract different users and determine their pattern of behaviour in social media. In the centre of Fig. 1b, there is an indicator that marks altruism (benevolence, kindness), i.e. mutual sympathy feeling, willingness to provide disinterested assistance.

Altruism is the central engine of social networks development because it creates communities based on trust and cooperation. The desire to provide disinterested help to others is not the only motive activity in social networks. There is a range of categories of users motivated by different goals (Tab. 1). Recently, the subject TMI was commented by the marketing director of Accenture Hamid Kastoev (Prokhorov, 2015) that the first person perceives social networks with caution, as something new, and trusts in this space a minimum of personal data, but then it enters his/her life and seems harmless listener like a personal therapist. A person begins to trust the network more personal information until he/she gets one or another negative experience. The fact that excessive frankness and openness in social networks is dangerous is repeatedly confirmed (for example, about $88 \%$ of sexually explicit photos exposed to social media are stolen and move on porn sites without notifying holders) (Prokhorov, 2015).

\section{Social networks as a tool to determine the} psychological portrait of personality. The psychological qualities of a person leave their imprint on his/her behaviour in social networks. On the basis of this statement, there can be solved the opposite problem. According to Shuotian Bai from the University of Chinese Academy of Sciences in Beijing, in 2012, a team of researchers has developed an online test to determine the psychological portrait of the human personality by pattern (Eng. Pattern from Lat. Patronus example to follow, style, design, pattern, shape, model, system - sustainable, context driven repetition of human thinking and behaviour to achieve certain results; a base unit of unconscious, a dedicated "automatism"; in a broader sense, any pattern, repetition of something), his/her behaviour in social networks such as Facebook or Renren (a popular social network in China), (Shuotian, Tingshao, \& Li, 2012). The researchers asked more than 200 Chinese students who have accounts in Renren to fill in the test called "Big Five Inventory", which was developed at the University of California (Berkeley) in 1990. Along with it, the developers studied Renren student pages fixing sex, age, and online behaviour profile: frequency of access to the social networks, emotional colouring and content of posts (written with humour or sadness, emotional or restrained, etc.). Further, they used statistical methods to identify the correlation between test results and user online behaviour in the social network. The description of a psychological portrait of personality was based on five categories of behaviour (A, C, E, N, O) Tab. 2. The authors of the test argue that online behaviour can be successfully used to determine the type of personality and give some examples of correlations. In particular, people with high aspirations for the organization and discipline often published issues with a request to clarify the location of the object or email address; the frequency of emoticons use proves extroversion degree; constant updating of status parameters suggests openness of the individual, etc. Based on the research described, the specialized social networking services are implemented. They predict what types of services will be increasingly in demand by persons with different structures of the individual. What type of products, what type of advertising, what kind of news, what kind of contacts are in demand by people of a particular category. Research methodology can detect the psychological profile associated with religious, political, and cultural characteristics of the users. The owners of social networks used these techniques for further commercialization of services. In practice, the "pure" types are rare; there usually occur combinations of the main categories. Moreover, at different times and in different social networks, the motivation of the same people is different.

\section{Features of social networks use in different} countries. The interesting question is about the behaviour of the citizens of different countries and continents in social networks depending on the economic and cultural characteristics of social networks users. In works (Global Web Index, 2009), (Bennett, 2012), (Prokhorov, 2015) there is 
presented infographics of the social networks global map by Global WebIndex, which

Table 2. Categories of individual behaviour in social networks according to (Shuotian, Bai, 2012)

\begin{tabular}{|c|c|c|}
\hline Name & Decryption & Explanation \\
\hline A & Agreeableness & $\begin{array}{l}\text { predisposition to assist, promote, show affection, seek cooperation } \\
\text { with the community members; }\end{array}$ \\
\hline C & Conscientiousness & predisposition to discipline, organization, focus on achieving results; \\
\hline $\mathrm{E}$ & Extraversion & $\begin{array}{l}\text { the presence of a high level of communication skills, confidence, and } \\
\text { a high degree of sociability; }\end{array}$ \\
\hline $\mathrm{N}$ & Neuroticism & the degree of emotional stability, control of impulsiveness and anxiety \\
\hline O & Openness & $\begin{array}{l}\text { the presence of pronounced intellectual curiosity, interest in innovation } \\
\text { and all kinds of changes. }\end{array}$ \\
\hline
\end{tabular}

describes how people from different countries actively come into contact with each other under different behavioural types of social networks:

- Messengers and Mailers (Write letters and messages). Users, who received the message, spread it out on the network to each other.

- Content Sharers (Those who share content). Users who exchange content through the content network.

- Joiners and Creators of Groups (visitors and groups creators). Users who create groups, manage them and join other groups.

A map of behavioural patterns of social networks users in different countries is based on the research conducted by GlobalWeblndex. External (largest) circles on the map indicate the number of active participants in social networks; their number is expressed in millions of people.

The research shows (Tab. 3) that in developed countries, such as the USA, UK, Germany, Canada, users are more focused on the preparation of messages and less on the separation of content, while in the developing countries with rapidly growing economies, such as Indonesia or China, users spend more time on content sharing and participation in groups (Global Web Index, 2009), (Bennett, 2012). Tab. 4 contains the key investigations of Global Web Index by the following criteria (Bennett, 2012):

1. Upload photos online.

2. Upload video online.

3. Manage a social network profile.

4. Write your own blog.

5. Use a micro-blogging service.

\section{Percentage with access.}

7. Percentage without access.

The representatives of Global Web Index have interviewed 32,000 web users in 16 countries to provide a unique international perspective analysis of web behaviour and social participation of the media worldwide (Prokhorov, 2015), (Global Web Index, 2009), (Bennett, 2012). There have been conducted studies on the impact of social communication forces and the role of brands on consumer behaviour. This story of users' behaviour provides a global snapshot of the active participation of the social web interface market. The data show the percentage of those who are active in each of the forms of social activity. The size of the collected data is the amount of the audience in millions. On globalwebindex.net, one can find causes and trends, different demographics that are involved in the analysis of user behaviour, what motivates the Internet users to meet their own interests on the Internet, and quantitative assessment of how brands should be active in social media (Fig. 2).

Commenting on the situation, one of the researchers Ivan Yardley makes the assumption (Prokhorov, 2015) that fast-growing markets increasingly show a pattern of conduct that encourages the spread of new ideas and, as a consequence, the rapid economic growth. Indirectly, this trend confirms the investigation made by Brian Uzzi: his popular lecture "Teaming up to drive scientific discovery" is available on Youtube, where it is said about generating of new discoveries, which are increasingly conducted by groups, and the role of researchers of single drops. At the same time, the development team is 
beyond the scope of research laboratories, institutions, and cities. Brian Uzzi states that creativity is, first of all, an internal quality of scientist, but the current studies show that an export/import of ideas begins to play an increasing role. Idea export and its use in a new area often lead to the invention (Prokhorov, 2015). The emphasis falls on the new area because the ideas move from one stable network group to another determines the given process.

Table 3. The main values of behavioural patterns of social networks users in different countries (Global Web Index, 2009), (Bennett, 2012), (Prokhorov, 2015)

\begin{tabular}{|l|c|c|c|c|c|}
\hline Country & $\begin{array}{l}\text { A number of active } \\
\text { participants, in MM }\end{array}$ & $\begin{array}{l}\text { Active online } \\
\text { users, \% }\end{array}$ & $\begin{array}{l}\text { Messengers and } \\
\text { mailers, \% }\end{array}$ & $\begin{array}{l}\text { Content } \\
\text { sharers, \% }\end{array}$ & $\begin{array}{l}\text { Joiners/creators of } \\
\text { groups, \% }\end{array}$ \\
\hline Canada & 11.72 & 49 & 54 & 43 & 26 \\
\hline The USA & 114.55 & 52 & 51 & 51 & 20 \\
\hline Mexico & 12.80 & 56 & 52 & 63 & 37 \\
\hline Great Britain & 19.27 & 46 & 44 & 40 & 28 \\
\hline Netherlands & 6.30 & 45 & 45 & 42 & 18 \\
\hline Poland & 12.03 & 58 & 48 & 46 & 26 \\
\hline Germany & 18.81 & 39 & 47 & 38 & 32 \\
\hline France & 15.92 & 41 & 57 & 45 & 28 \\
\hline Italy & 12.66 & 44 & 38 & 49 & 36 \\
\hline India & 35.08 & 63 & 50 & 64 & 49 \\
\hline Brazil & 33.49 & 65 & 54 & 51 & 34 \\
\hline Spain & 10.10 & 42 & 47 & 45 & 36 \\
\hline Philippines & 14.43 & 77 & 57 & 72 & 45 \\
\hline Indonesia & 18.83 & 76 & 57 & 66 & 52 \\
\hline Malaysia & 11.50 & 68 & 54 & 63 & 41 \\
\hline Russia & 26.06 & 64 & 56 & 62 & 45 \\
\hline Singapore & 1.96 & 61 & 48 & 57 & 32 \\
\hline Hong Kong & 2.56 & 53 & 39 & 56 & 33 \\
\hline China & 155.29 & 48 & 47 & 53 & 34 \\
\hline Australia & 23.06 & 47 & 45 & 43 & 30 \\
\hline South Korea & 10.83 & 32 & 23 & 33 & 11 \\
\hline Ukraine & 16.36 & 62 & 56 & 62 & 45 \\
\hline Japan & 13.08 & 16 & 13 & 12 & 8 \\
\hline
\end{tabular}

Table 4. Social Web Involvement (Global Web Index, 2009), (Bennett, 2012), (Prokhorov, 2015)

\begin{tabular}{|c|c|c|c|c|c|c|c|c|c|c|c|c|c|c|}
\hline \multirow{2}{*}{$\begin{array}{l}\text { Country } \\
\text { Access/Users }\end{array}$} & \multicolumn{2}{|c|}{$1, \% / m$} & \multicolumn{2}{|c|}{$2, \% / m$} & \multicolumn{2}{|c|}{$3, \% / m$} & \multicolumn{2}{|c|}{$4, \% / m$} & \multicolumn{2}{|c|}{$5, \% / m$} & \multicolumn{2}{|c|}{$6, \% / m$} & \multicolumn{2}{|c|}{$7, \% / m$} \\
\hline & $A$ & U & A & $U$ & A & $U$ & A & U & A & U & A & $U$ & A & $U$ \\
\hline Canada & 40.9 & 9.0 & 14.9 & 3.3 & 46.2 & 10.2 & 10.6 & 2.3 & 5.1 & 1.1 & 46.2 & 10.2 & 53.8 & 11.9 \\
\hline Great Britain & 38.2 & 15.7 & 11.5 & 2.4 & 42.6 & 15.9 & 8.4 & 5.5 & 5.3 & 4.6 & 42.6 & 15.9 & 57.4 & 21.4 \\
\hline The USA & 42.6 & 79.2 & 15.3 & 23.5 & 44.2 & 92.1 & 12.8 & 17.6 & 7.0 & 10.7 & 44.2 & 92.1 & 55.8 & 116.3 \\
\hline Mexico & 52.9 & 6.4 & 22.1 & 1.6 & 40.2 & 4.8 & 25.6 & 3.1 & 13.7 & 1.6 & 52.9 & 6.4 & 47.1 & 5.70 \\
\hline Netherlands & 37.0 & 4.8 & 10.0 & 1.3 & 36.2 & 4.7 & 10.1 & 1.3 & 3.5 & 0.45 & 37.0 & 4.8 & 63.0 & 8.17 \\
\hline Spain & 39.4 & 7.4 & 16.2 & 3.1 & 35.8 & 6.7 & 17.2 & 3.2 & 7.5 & 1.4 & 39.4 & 7.4 & 60.6 & 11.4 \\
\hline Brazil & 54.0 & 16.2 & 34.0 & 10.2 & 59.6 & 17.9 & 20.7 & 6.2 & 14.2 & 4.3 & 59.6 & 17.9 & 40.4 & 12.1 \\
\hline
\end{tabular}




\begin{tabular}{|c|c|c|c|c|c|c|c|c|c|c|c|c|c|c|}
\hline \multirow{2}{*}{$\begin{array}{l}\text { Country } \\
\text { Access/Users }\end{array}$} & \multicolumn{2}{|c|}{$1, \% / m$} & \multicolumn{2}{|c|}{$2, \% / m$} & \multicolumn{2}{|c|}{$3, \% / m$} & \multicolumn{2}{|c|}{$4, \% / m$} & \multicolumn{2}{|c|}{$5, \% / m$} & \multicolumn{2}{|c|}{$6, \% / m$} & \multicolumn{2}{|c|}{$7, \% / m$} \\
\hline & $A$ & $U$ & A & $U$ & A & $U$ & A & $U$ & A & $U$ & $A$ & U & $A$ & $U$ \\
\hline Italy & 43.3 & 9.1 & 20.9 & 4.4 & 35.8 & 7.6 & 19.4 & 4.1 & 12.3 & 2.6 & 43.3 & 9.1 & 56.7 & 11.9 \\
\hline Germany & 31.6 & 13.4 & 8.5 & 3.6 & \begin{tabular}{|l|}
32.7 \\
\end{tabular} & 13.9 & 10.0 & 4.3 & 5.7 & 2.4 & \begin{tabular}{|l|}
32.7 \\
\end{tabular} & 13.9 & 67.3 & 28.6 \\
\hline France & 27.5 & 10.5 & 9.5 & 3.6 & 29.3 & 11.2 & 9.5 & 3.6 & 3.8 & 1.4 & 29.3 & 11.2 & 70.7 & 27.00 \\
\hline India & 63.9 & 22.4 & 36.2 & 12.7 & 57.5 & 20.1 & 34.0 & 11.9 & 24.0 & 8.4 & 63.9 & 22.4 & 26.1 & 9.15 \\
\hline Russia & 58.9 & 18.8 & 39.6 & 12.6 & 48.0 & 15.3 & 18.3 & 5.8 & 12.0 & 3.8 & 58.9 & 18.8 & 41.1 & 13.1 \\
\hline Australia & 39.1 & 4.9 & 11.9 & 1.5 & 40.0 & 5.0 & 11.4 & 1.4 & 5.6 & 0.7 & 40.0 & 5.0 & 60.0 & 7.50 \\
\hline China & 60.3 & 117.7 & 28.7 & 55.9 & 27.3 & 53.2 & 46.0 & 89.7 & 21.3 & 41.5 & 60.3 & 117.7 & \begin{tabular}{|l|}
39.7 \\
\end{tabular} & 77.50 \\
\hline South Korea & 53.1 & 14.9 & 19.5 & 5.5 & 15.6 & 4.4 & 39.9 & 11.2 & 14.0 & 4.0 & 53.1 & 14.9 & 46.9 & 13.20 \\
\hline Japan & 19.5 & 12.7 & 5.7 & 3.7 & 14.9 & 9.7 & 24.5 & 15.9 & 8.0 & 5.2 & 24.5 & 15.9 & 75.5 & 48.90 \\
\hline
\end{tabular}

The process of studies "collectivization" began before the era of the Internet and is developing by strong rates along with the process of emergence of more powerful means of collective communication. The increase in the number of group research and their members is observed primarily in technical disciplines and hardly noted in the humanities (Prokhorov, 2015). With the withdrawal that the online communication profile with an active content stratification promotes ideas and, consequently, economic development, we should agree only in part as there are additional considerations (Prokhorov, 2015).

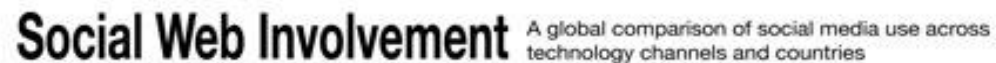

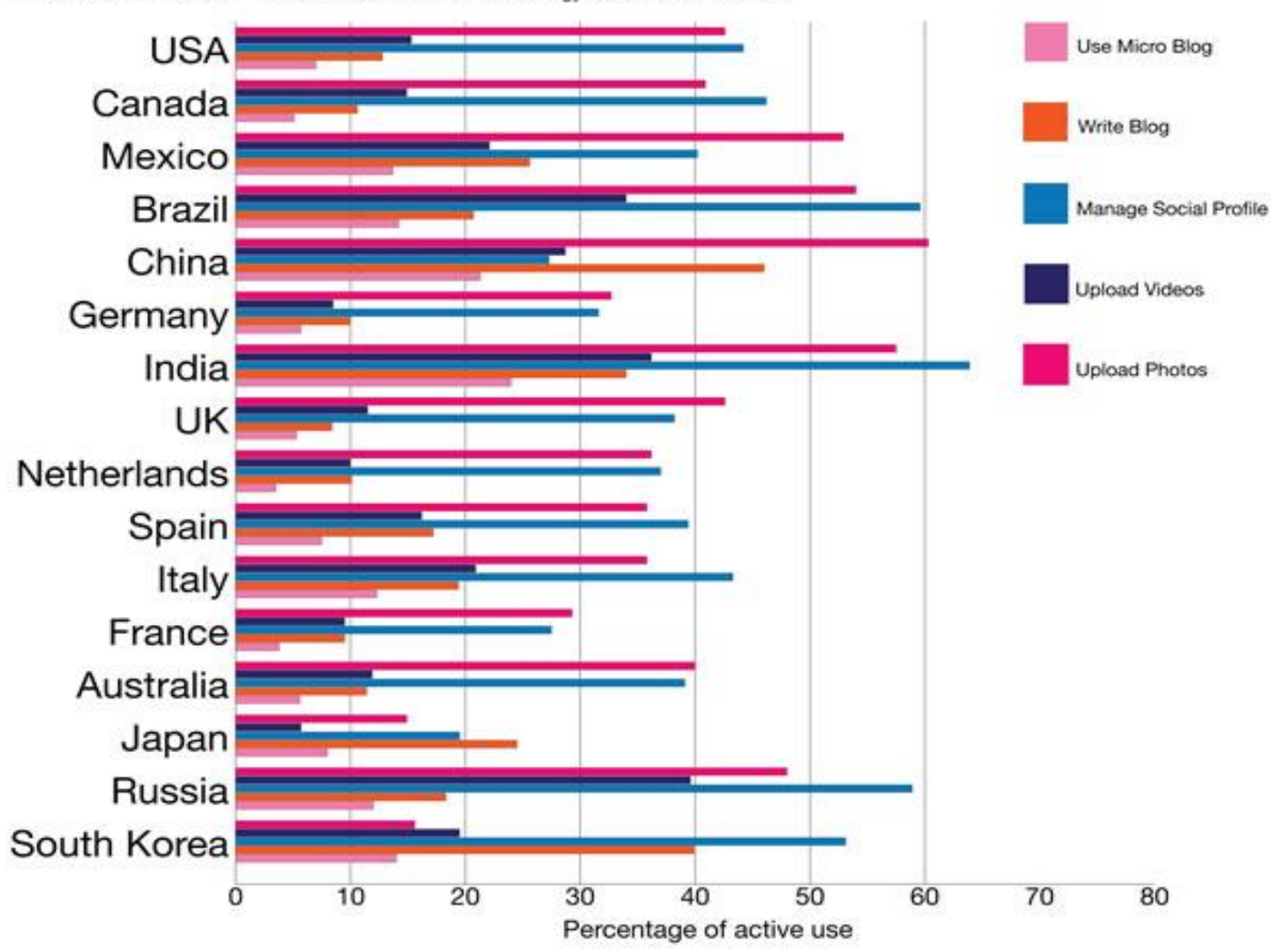

Fig. 2. The behaviour of users from different countries in social networks (Bennett, 2012)

To a large extent, the development of science and IT in society and economy happens in private commercial competitive organizations operating in a environment. If knowledge is 
accumulated within a closed network structure (organization), where these ideas are recorded, protected from leakage, and patented, they do not make sense to invest forces and money. Therefore, one should consider the dialectic process, i.e. active information sharing as well as protection of corporate interests of the companies that invest in new promising IT. When looking at network members that exchange information, in addition to corporations, one should mention social networks owners. They do not only stimulate the networking, generating new knowledge, but also blur the boundaries of closed internal corporate communities. To some extent, the process of absorption of new knowledge is beneficial to social networks owners. Accumulating large amounts of information, they get a unique opportunity to identify new patterns in accumulated data using the methods of statistical processing of large volumes of content, including commercial, which employees of corporations unwittingly endure beyond the perimeters of organizations engaging in professional discussions on the pages of social networks (Fig. 3). The country, in which a global social network is based (through security structures), gets better access to the resource than other countries.

a)
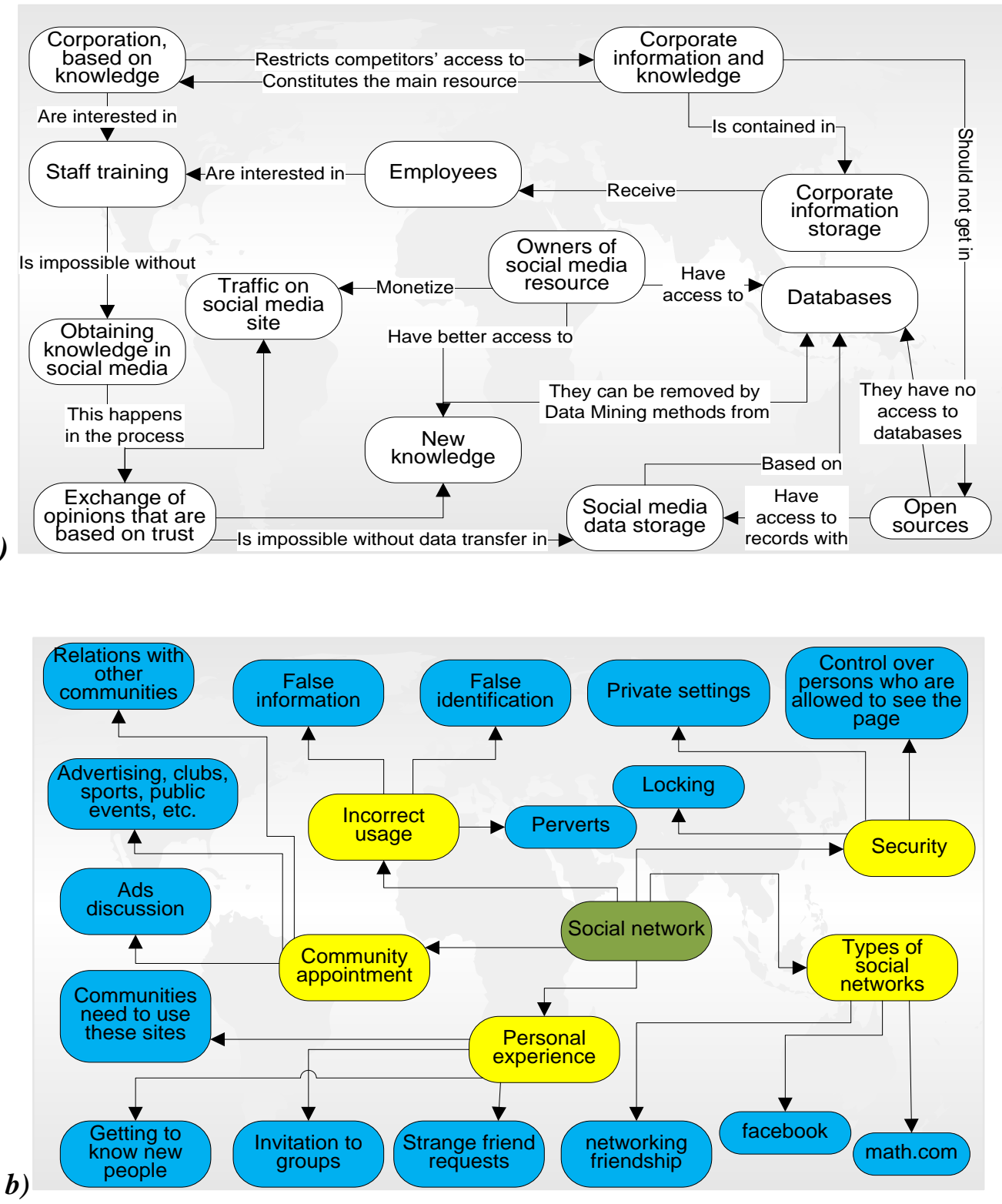

Fig. 3. a) Conflict of interest in attracting corporate employees in general profile social networks and b) social networks maps concept (Source: (Prokhorov, 2015)) 
5. Dissemination of information in social networks (the role of click and bridges) through the exchange of information between different network profiling communities and their associations in general profile social networks because it is very important to describe the spread of information in social networks. The combination of profiling communities in general profile social networks, such as Facebook and Twitter, leads to some psychological problems and attributes this to the fact that people do not have a common universal identity; on the contrary, the human person is multifaceted, and each edge faces different communities manifesting itself differently in each of them (Prokhorov, 2015). In a relaxed atmosphere with friends, persons use specific vocabulary and judgment, but in case a guest or woman appears, a conversation becomes different; and if the team consists of not only likeminded people, the other is not only the language but also the manner of presentation and tons, etc. Personality plays different roles in various social environments. Therefore, an attempt to combine them into one space leads to problems. For example, a person has an account on Facebook, where basically communicate with his/her friends and peers, and then he/she must be connected to the network of parents or children. It is likely that he/she is not ready to share all the statements with a new audience. Or, for example, a chief wants to become a friend on Facebook, and then a subordinate probably will not want to open all the information to him.

The problem of discomfort in general profile social networks can occur more frequently: it depends on the person's conformist degree. Anyone who keeps his/her own judgments - political, religious, national - regardless of the opinions of others, is ready to publicly declare and defend them in different communities. Therefore, he/she will feel less discomfort in general profile networks. On the contrary, a practice to "belong" to different communities by the principle "to run the hare and hunt with the hounds" will cause problems. Profiling social networks will not be fully absorbed by general profile networks, as communities are united by the old principle of union supporters. And the problems are discussed within a closed network community. Closed corporate networks, which unite against competitors, inspectors, etc., are constructed by the same principle (Fig. 4).

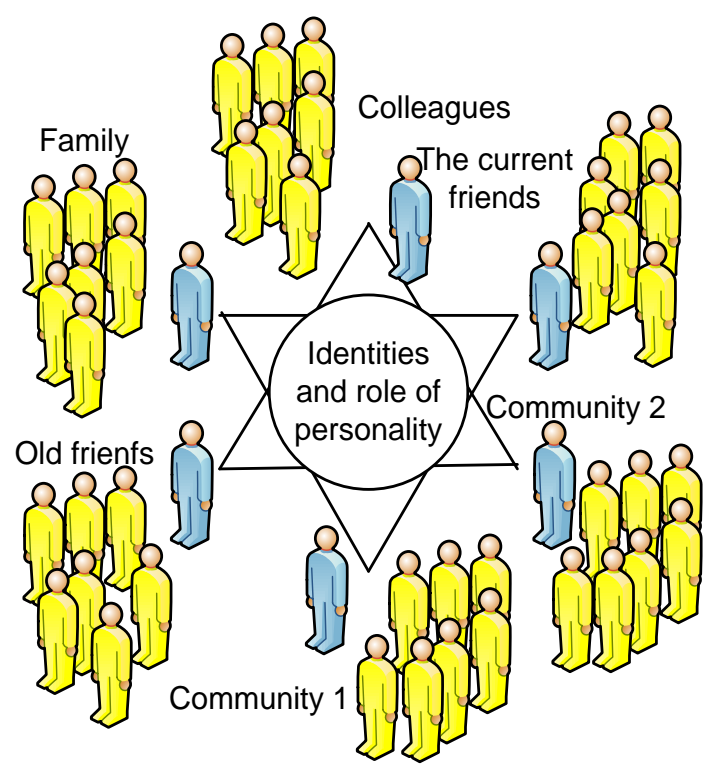

Fig. 4. Personalities in general profile social networks are different communities' members

The possibility of profile network communities intersection does not only creates problems but also opens new possibilities for users. General profile network gives its members the opportunity to cross social barriers. For some people, the opportunity to be with his chief in one information space of the private character is not so much a psychological problem as a new opportunity to learn more about him/her, found necessary people in his/her circle, and make friends with them, for example, on the basis of common hobbies. General profile social networks give a possibility to be in the right network space without various complexities and costs. The possibility of different social layers intersection moves the spread of information in social networks through the socalled bridges that connect different communities (clicks) and are information conductors.

6. Social Commerce Psychology Apart from the psychological and social reasons, patterns of communication and information exchange in social networks determine the level of activity and principles of user behaviour in social commerce (Tab. 5) (Lovakov, 2013), (Alizar, 2012), (Shuotian, Bai, 2012), (Global Web Index, 2009). 
Table 5. Principles of user behaviour in social commerce social networks (Prokhorov, 2015)

\begin{tabular}{|c|c|c|}
\hline Name & Decryption & $\begin{array}{l}\text { The explanation according } \\
\text { to Briansolis }\end{array}$ \\
\hline $\begin{array}{l}\text { Crowd } \\
\text { opinion }\end{array}$ & $\begin{array}{l}\text { People tend to look at what they do or other did to overcome the } \\
\text { anxiety associated with taking wrong decisions (in this case, the } \\
\text { wrong purchase). }\end{array}$ & $\begin{array}{l}81 \% \text { of buyers in social } \\
\text { networks ask advice } \\
\text { regarding expedience of } \\
\text { purchasing a product. }\end{array}$ \\
\hline Authorities & $\begin{array}{l}\text { For customers, it is important to appeal to the authorities - } \\
\text { experts in their field. }\end{array}$ & $\begin{array}{l}77 \% \text { of online shoppers are } \\
\text { turning to reviews of } \\
\text { professionals in the social } \\
\text { media to make the right } \\
\text { decision. }\end{array}$ \\
\hline $\begin{array}{l}\text { Less } \\
\text { is better }\end{array}$ & $\begin{array}{l}\text { Social networks users, as well as buyers in general, tend to give } \\
\text { more weight to service with limited access. Phrase "While } \\
\text { supplies last" is often heard in advertising. Operated by fear of } \\
\text { losing benefits and desire to belong to an elite group, network } \\
\text { users are ready to enter the communities that will have an access } \\
\text { to exclusive offers. }\end{array}$ & $\begin{array}{l}77 \% \text { of people wanted to get } \\
\text { an exclusive offer of limited } \\
\text { party goods acquisition } \\
\text { through Facebook. }\end{array}$ \\
\hline $\begin{array}{l}\text { Keep an eye } \\
\text { on those who } \\
\text { trust }\end{array}$ & $\begin{array}{l}\text { People tend to have business with those who are sympathetic to, } \\
\text { trust, and this is particularly true in social media. People tend to } \\
\text { share information about good deals, interesting trends in the } \\
\text { group of their community network to enhance the degree of trust } \\
\text { to their own person and raising their authority in the group. }\end{array}$ & $\begin{array}{l}\text { Almost } 50 \% \text { of consumers } \\
\text { made a purchase on the } \\
\text { advice received from their } \\
\text { community on the social } \\
\text { network. }\end{array}$ \\
\hline Permanence & $\begin{array}{l}\text { Faced with uncertainty, people tend to minimize risks by referring } \\
\text { to the proven solutions. Frequently, an offer to buy a new brand } \\
\text { product at a lower price does not work because of the given } \\
\text { pattern in the customers' behaviour. Confidence in the brand } \\
\text { forms new purchases pattern. }\end{array}$ & $\begin{array}{l}62 \% \text { of online buyers show } \\
\text { loyalty to the brand because } \\
\text { of a positive experience of } \\
\text { online shopping. }\end{array}$ \\
\hline $\begin{array}{l}\text { Mutual } \\
\text { assistance }\end{array}$ & $\begin{array}{l}\text { One of the most important capitals in the social networks is a } \\
\text { kindness. Those, who help friends in the community, create } \\
\text { goodwill reserve to their selves. People tend to balance the desire } \\
\text { to uphold social justice and give thanks for services, even if they } \\
\text { did not ask for a favour. }\end{array}$ & $\begin{array}{l}\text { Every month, } 25 \text { billion pieces } \\
\text { of content are shared on } \\
\text { Facebook. }\end{array}$ \\
\hline
\end{tabular}

\section{SCIENTIFIC RESULTS ANALYSIS}

Software system functionality. The mechanism for using functions allows describing the features of this information system (Tab. 6). To improve the quality of this information work, we introduce the concept "function attributes", i.e. data elements that provide additional information about each function.

Table 6. Functions of the system

\begin{tabular}{|l|l|l|}
\hline № & \multicolumn{1}{|c|}{ Name } & \multicolumn{1}{c|}{ Description (function value) } \\
\hline 1 & Personalization & $\begin{array}{l}\text { Each program should be strictly personalized for a particular person; } \\
\text { i.e. each user must create an account in order to simplify the } \\
\text { information system operation }\end{array}$ \\
\hline 2 & $\begin{array}{l}\text { Personalized information } \\
\text { protection }\end{array}$ & $\begin{array}{l}\text { Creating an account, user will give confidential data that must be } \\
\text { protected from outsiders' encroachment }\end{array}$ \\
\hline 3 & Primary data analysis & $\begin{array}{l}\text { Collection and processing of data from social network profile. Filtering } \\
\text { by key indicators }\end{array}$ \\
\hline 4 & Statistical analysis of data & $\begin{array}{l}\text { Identification of key patterns in the collected data and statistical report } \\
\text { formation }\end{array}$ \\
\hline
\end{tabular}




\begin{tabular}{|c|c|c|}
\hline № & Name & Description (function value) \\
\hline 5 & Education & $\begin{array}{l}\text { On the basis of the collected data and previous experience - } \\
\text { preliminary conclusions improving or new programs creation }\end{array}$ \\
\hline 6 & Processed data storage & Providing access to user's preliminary analysis data \\
\hline 7 & Character analysis & Identification of key indicators of human nature \\
\hline 8 & Temperament analysis & Identification of key indicators of human temperament \\
\hline 9 & Emotionality analysis & Identification of key indicators of human emotionality \\
\hline 10 & Self-assessment analysis & Identification of key indicators of human self-assessment \\
\hline 11 & Volitional qualities analysis & Identification of key indicators of human volitional qualities \\
\hline 12 & Social skills analysis & Identification of key indicators of human social skills \\
\hline 13 & $\begin{array}{l}\text { Comparison and adjustment of } \\
\text { results }\end{array}$ & $\begin{array}{l}\text { Comparing previous results with current ones on the basis of the } \\
\text { comparison of functions No. } 7-12 \text {, and, if necessary, their adjustment. }\end{array}$ \\
\hline 14 & General conclusions formation & Generalization of individual's psychological state. \\
\hline 15 & Formation of recommendations & $\begin{array}{l}\text { Determination of appropriate strategies to communicate with a person } \\
\text { or other interaction features. }\end{array}$ \\
\hline 16 & Informing about research error & Detection of error in the research and informing about it \\
\hline 17 & Help with use of the program & Creating a complete reference for user \\
\hline 18 & $\begin{array}{l}\text { Correction of analysis possible } \\
\text { errors }\end{array}$ & $\begin{array}{l}\text { Possibility for certain users, who have the necessary authority for this } \\
\text { purpose, to correct errors in the mechanisms of psychological analysis } \\
\text { or results }\end{array}$ \\
\hline 19 & $\begin{array}{l}\text { Freud's determination of } \\
\text { psychological type }\end{array}$ & Typification of personality under Freud's studies and classification \\
\hline 20 & $\begin{array}{l}\text { Jung's determination of } \\
\text { psychological type }\end{array}$ & Typification of personality under Jung's studies and classification \\
\hline 21 & $\begin{array}{l}\text { Encyclopaedia and information } \\
\text { on psychology }\end{array}$ & $\begin{array}{l}\text { Creating the required guide that contains a description of all } \\
\text { psychological characteristics. }\end{array}$ \\
\hline 22 & Data backup & $\begin{array}{l}\text { Data backup function for cases when the data may be lost } \\
\text { (personalized entity data, survey results) }\end{array}$ \\
\hline 23 & $\begin{array}{l}\text { Data access function and } \\
\text { comparison of data from } \\
\text { different social networks }\end{array}$ & $\begin{array}{l}\text { Ability of an interactive comparison of data from different social } \\
\text { networks }\end{array}$ \\
\hline 24 & Personal analysis & $\begin{array}{l}\text { Ability to analyze personalized user individual analysis on the basis of } \\
\text { his/her social networks accounts, as well as requests. }\end{array}$ \\
\hline 25 & $\begin{array}{l}\text { Search for people conducted } \\
\text { under certain types or } \\
\text { preferences }\end{array}$ & $\begin{array}{l}\text { Implementation of search or filtering people on the basis of specific } \\
\text { preferences }\end{array}$ \\
\hline
\end{tabular}

Summing up all the above, it should be noted that since there are no qualitative and comprehensive solutions currently on IT, which offer this problem solving, it is extremely important. The main goal of internal research in this area is the evaluation of modern society psychological state. It is possible to create serious IS's that, on the basis of information from social networks, will be able to determine and predict a so-called "temperature", i.e. a general state of society at a certain time. This will help prevent different kinds of problems associated with the social discontent of the population, etc. I consider that this decision may find its application for solving a wide range of problems and challenges in various areas of the modern world.
4 DESCRIPTION OF THE SYSTEM REQUIREMENTS ACCORDING TO THE RUP METHODOLOGY

1. Persons interested in the precedent and their requirements:

- a registered user wants to quickly find out the psychological state of a person without spending a lot of time;

- a person whose psychological analysis is carried out: is not against the fact that his/her own data will be analyzed (i.e. provides open access to his/her account);

- project administration wants to have full information on the operation of IS. 
2. IS user is the main actor of this precedent: it is an ordinary man who is a registered user and performs psychological analysis of different individuals using IS.

3. Precedent preconditions:

- IS must be active;

- user must successfully undergo authorization procedure (or registration) in the IS;

- data of the person, whose psychological analysis is under investigation, should be open.

4. The main successful scenario:

- the user begins a new psychological research;

- the user enters the name or ID of the person whose account in the social network will be explored;

- IS searches for human as well as his/her account information sample;

- IS carries out the analysis of data;

- IS displays detailed results of the analysis on the screen.

5. Expanding basic scenario or alternative streams:

\subsection{Wrong person identifier}

- IS informs the user about an error and cancels data input for the desired person.

- If necessary, a user can ask IS and obtain (as a hint) a list of all possible people identifiers (e.g., those that begin with a certain letter or number).

- A user repeatedly enters correct ID of the person.

- IS searches and displays the individual account of the found person (this is the point of returning to the main scenario).

5.2 A person is not found

- IS informs the user about an error and cancels data input for the desired person.

- If necessary, a user can ask IS and obtain (as a hint) a list of all possible people identifiers (e.g., those that begin with a certain letter or number).

- If a person is found again, IS notifies the user about an error and goes into the initial state.

5.3 A person has limited the access to his/her own data

- IS notifies the user about access error.

- IS outputs a request to search any other person or returns to its original state.
6) Postconditions: a list of conditions for compulsory execution in case of successful basic scenario (if all the interests of all stakeholders of paragraph 2 are satisfied):

- Data on personality psychological analysis are processed and stored in the IS.

- All the necessary recommendations and conclusions are made.

- A user has finished working in this session.

- A session is successfully recorded in IS database.

7) Special scenarios: to provide:

- the highest reliability of all sessions' processing.

- the possibility of user interface IS localization.

- $\quad 100 \%$ ability to save data.

- a special access to a privileged group of users to correct errors in functioning.

8) List of necessary technologies and extra devices: IS should be

- developed as a WEB-oriented system.

- submitted as a supplement to all existing browsers.

- designed for all existing desktop and mobile operating systems.

The aim of this work is to create IS of individual psychological analysis. This system is designed to determine the main features of the "Big Five" using analysis of user messages on Twitter. The main users of the system are Internet users, in particular, as well as PC users in general, who want to quickly and easily learn some psychological characteristics of the individual social network user. Also, various recruitment companies can act as users, since the information gathered during this system operation can be used to find a necessary person to a certain position. The interface of this software solution has to be simple and intuitive even to weak PC users. The system should be integrated with the Internet to collect messages in social networks and other support services. The objectives of the given information system are as follows:

- user authentication for access to further work with the system;

- user authorization on Twitter;

- $\quad$ finding the appropriate user;

- analysis of the required user messages;

- easy viewing of analysis results.

The main input data for the system functioning are: 
- personal user information - username, password, Twitter authentication data;

- messages of the user who is under analysis on Twitter.

IS should have the following opportunity: user authorization; user authorization on Twitter; user interface management; easy view the analysis results.

The result of work is the IP submitted as a desktop application, which is also the Internet service and allows analyzing the psychological state of a particular user on Twitter through his/her messages. This system should allow the user to store data analysis of the certain user as well as analyze other users of the social network.

The main issue of this paper is message analysis of specific Twitter user. There are many different methods of text analysis to determine one or another aspect of human nature: from habits and preferences to a specific and thorough analysis of the individual. It makes sense to consider such methods of text analysis:

- Content analysis - a type of document review. This method lies in systematic and reliable sequence to identify specific items of content of the particular array of documents with further data quantitative processing. It is used to study arrays of similar documents, large amounts of text, most of all - texts of mass communication. It is applied in determining results of questionnaires, conducting various interviews, etc.

- Morphological analysis - allows detecting morphological interpretation of each word of the text. This type of analysis is the basis for other, more fundamental types of text analysis.

- Semantic analysis - a method that allows building the semantic structure, consists of semantic nodes and semantic relationships.

- Intent analysis - a relatively new method that is based on the fact that the behaviour of each individual in society is intentionally-directed and has a particular recipient. Intension - a subjective focus on a particular subject or activity.

- Psychosemantic - a set of methods by which it is possible to determine the value or meaning of a word, object, or phenomenon.
There are some differences in detecting psychological content by means of intent analysis and psychosemantic. Along with the release of additional common factors, there are determined additional structures, and the relationship between them can not be taken into account when using these methods separately. The psychosemantical method basically detects unconscious tendencies, personal intentions. Combining these methods will enrich the analysis of the psychological meaning of the text.

Another problem is the methods of processing large volumes of text data. It is worth mentioning that conventional search algorithms are not very suitable for text data. Here one should use other methods. Some of them are reviewed below.

Formally, string search is defined as follows. Suppose that there is a specified array $\mathrm{T}$ with $\mathrm{N}$ elements and array $\mathrm{W}$ with $\mathrm{M}$ elements, and $0<M \leq N$. String search finds the first occurrence $\mathrm{W}$ in $\mathrm{T}$, the result will be considered index I, which indicates the beginning of the first line (from the array T) match with the image (word). For example, it is necessary to find all the occurrences of sample $W=A B A A$ in the text $T=$ abcabaabcabca. The sample enters the text only once, with the shift $S=3$, the index $I=4$.

Direct search algorithm.

1. Suppose I-1;

2. Compare I symbol of the array $T$ to the first symbol of array $\mathrm{W}$.

3. If character coincided, then it is needed to compare the second character, the third character, etc.

4. If a character did not match, then it is needed to increase by 1 and go to step 2 .

Algorithm completion terms:

1. M successive comparisons are successful.

2. If I $+M>N$, then the desired word is not found.

3. In the worst case, the complexity of the algorithm is $O\left(N{ }^{*} M\right)$.

The disadvantages of this algorithm are:

- The high complexity of the algorithm (up to $\left.\Theta\left((N-M+1){ }^{*} M\right)\right)$;

- If the characters did not match, the search begins with the first character of the sample and therefore can include $T$ symbols, which have been previously reviewed. 
- Information on T text, which we receive while checking $S$ shift, is not used when testing these shifts.

KMP algorithm (Knuth-Morris-Pratt algorithm). This algorithm actually requires $\mathrm{N}$ comparisons only, even in the worst case. After a partial match of the initial part of $W$ array with the relevant characters in T-string, in fact, it becomes known the first part of the line, and it is possible to determine some properties (based on the array $\mathrm{W})$, through which it is possible to quickly move through the text. The idea of KMP search lies in the idea that each time when there is a difference between two text characters and the array is shifted to all distance covered since smaller shifts can not lead to full algorithm takeoff. KMP search features:

- there should be approximately $(N+M)$ character comparisons to obtain results;

- KMP search scheme is really successful only when unsuccessful attempts were preceded by a certain number of matches. Only, in this case, the image shifts by more than one character. Unfortunately, coincidences occur much less frequently than differences. In most texts, the gain that may be obtained from KMP search is actually quite small.

Boyer-Moore algorithm (BM search). In practice, BM search algorithm is most effective if the array $\mathrm{W}$ is long, and capacity of the alphabet is large enough. At the core of BM search is the following idea: comparison of characters starts from the end of the array instead of the beginning, i.e. comparison of specific individual characters takes place from right to left. Then using some heuristic procedures we calculate a shift to the rights. Then again begin to compare characters from the end of the sample. This method does not only improve handling even in the worst case but also gives a bonus for intermediate situations. In most cases, except for specially compiled examples, BM search requires much less $\mathrm{N}$ comparisons. Under the most favourable circumstances, when the last character of the sample always falls on the character of the text, which is not the same, the number of comparisons is (N/M), in the worst case - O $\left((N-M+1){ }^{*} M+p\right)$, where $p-$ alphabet power. Therefore, to work out user's Twitter posts, first, it was chosen combining intent analysis and psychosemantics as the most effective means of determining the specific features of the user, and secondly, they applied BM search algorithm, which proved to be the most effective of all the above algorithms and is not too difficult to implement.

Method of personality psychological state cut-off consists of the following algorithms

1. Personalization (system user authorization/identification, choice of social network, which will carry out analysis, search, and authorization/identification of the individual analyzed in this network, as well as system user personalization in this network to provide access to data).

2. Search for people conducted under certain types or preferences

3. Search and gain access to personalized information and personal activity history in social networks

4. Data access function and comparison of data from different social networks

5. Collection and primary analysis of analyzed personality data (history, profile, posts, comments, likes, communities, etc.)

6. Formatting and storage of data that are worked out at all stages

7. Statistical processing and data filtering

8. Content analysis of text to find marked words

9. System training according to the conducted content analysis

10. Preliminary analysis of individual data and building dispositional personality model under "Big Five" main parameters

a. Extraversion/introversion analysis of the analyzed personality;

b. Goodwill analysis of the analyzed personality;

c. Good faith analysis of the analyzed personality;

d. Neuroticism analysis of the analyzed personality;

e. Openness experiences analysis of the analyzed personality.

11. The main analysis of the results of the preliminary analysis and the presence of marked words and activity in social networks

a. Individual character.

b. Individual temperament

c. Individual emotionality

d. Individual self-esteem

e. Individual volitional qualities 
f. Individual social qualities

12. Correction of analysis possible errors

13. Comparison with templates and results' adjustments according to the results of the conducted analysis

14. Freud's determination of psychological type

15. Jung's determination of psychological type

16. Data backup

17. Informing about research error

18. Formation of general conclusions and recommendations

The main results of the formation of general conclusions and recommendations depend on the correct conduct of text content analysis to find the marked words, the algorithm of which is as follows:

Stage. 1. Determining a set of criteria for the analyzed text content.

Step 1. Formation of such criteria as source type (a type of social network, public and/or private content, communities, etc.); content type (chat dialogs, history, profile data, shared content set, active involvement of friends, posts, comments, likes, activity in communities, etc.); personality being under analysis.

Step 2. Determining a size (scope/length), the frequency of occurrence, method/distribution place and time of content appearance.

Step 3. Determining of the array and marked words according to the category of psychological analysis of the "Big Five" main parameters.

Step 4. Creation, development, completion, modification of marked words dictionaries, blocked words, text classification rules under psychological parameters.

Step 5. Determining content filtering rules under existing criteria.

Stage. 2. The initial analytical-statistical sampling and content sample formation under limited sample from larger array criteria.

Stage. 3. Choosing linguistic text analysis unit to identify marked words on the basis of "Big Five" parameters.

Step 1. Identifying meaningful items of text content linguistic analysis (word, phrase, sentences subject, like, post, proof of friendship, idea, author, character, social situation, text part that is clustered under analysis category content).

Step 2. Formation of linguistic requirements for selecting analysis units: is large enough to interpret meaning; is small enough to not interpret many meanings; is easily identified; a number of units are large enough to hold the sample.

Step 3. Formation of rules of identified linguistic units' morphological analysis to determine the basis of words taking into account a frequency of their appearance in the text.

Step 4. Formation of the rules of identified linguistic units' syntactic analysis carrying out taking into account the analyzed text language features.

Step 5. Formation of the rules of identified linguistic units' semantic analysis carrying out taking into account the marked phrases formation peculiarities.

Step 6. Formation of the rules of commonly used marked words identifying among the set of identified linguistic units of the analyzed text excluding blocked words.

Step 7. Formation of the rules of blocked words identifying among commonly used linguistic units.

Stage. 4. Marking of text content accounts analysis units

Step 1. If units of account coincide with units of analysis, then it is needed to find frequencies of the selected content unit, otherwise, go to step 2 . Step 2. On the basis of the analyzed content, moderator proposes units of account, for example, the length of texts; text area filled with meaningful units; the number of lines (paragraphs, characters, text columns); size/type of file; the number of pictures of certain content/story, etc.

Stage. 5. Comparison of meaningful units of analysis with units of account.

Step 1. Classification by groups of weight with an assessment of meaningful categories in the total volume of the text. A classifier is an overall table, which summarizes all categories of analysis and analysis units. Unit expression units are fixed.

Step 2. Statistical calculations of content clarity and attractiveness.

Stage. 6. Development of text content analysis tool.

Step 1. Creating a protocol encoded content for compact presentation of data and quick comparison of all content analysis results.

Step 2. Filling a content protocol by properties (author, time of publication, volume, etc.).

Step 3. Filling a content protocol by labelled words according to the "Big Five" parameters.

Step 4. Filling a content protocol by the results of its analysis (the amount of use certain analysis 
units in it and conclusions regarding the categories of analysis). Protocol of each content is filled on the basis of the count of its registration cards data.

Stage. 7. Development of content analysis table. Table type is determined in the form of coordinated and subordinated categories of analysis: each category (issue) provides a number of features (answers), according to which there is a quantification of the text content.

Stage. 8. Development of content analysis coding matrix.

Step 1. If a sample size is $\geq k$ units, then a set of matrix sheets is under analysis, otherwise, perform step 2.

Step 2. If a sample size is $<k$ units, then a bivariate analysis is conducted. In this case, the coding matrix is formed for each content.

Stage. 9. Analyzing the text according to established coding matrixes.

Stage. 10. Results interpretation. Identify and evaluate the characteristics of the content on the basis of the statistical set of coefficients calculated over a period of time allocated for a certain category. Covers all extracted pieces of text, and the conclusions are based not on the part of the results but are taken into account as they are, without exception.

We suggest using syntax analysis algorithms of Ukrainian and English processing text and content analysis (the third step of the algorithm) of large volumes of text data and marked words analysis.

\section{CONCLUSIONS PERSPECTIVES OF FURTHER SCIENTIFIC STUDIES}

In the course of this work, it was carried out creation and development of the information system through which it is possible to conduct a psychological analysis of the individual using his/her Twitter messages. The system helps to automate information gathering project, as well as obtaining and saving the results. It was carried out the analysis of the subject area, as well as considered a variety of information systems based on the certain principle. There was conducted an analysis of the generally known methods and criteria of information systems development. Also, there was also conducted an analysis of the system functionality. There were foreseen the functions that would exist in the system and their usefulness. There was also carried out a systematic analysis of the information system of personality psychological analysis, as well as described the subject area problem and defined project purpose. Using systematic approach basic principles, there were described requirements created by the information system.

There was applied RUP methodology, by means of which there were defined and described the main precedents of the system and its actors. There were constructed use case diagrams, as well as diagrams of activity, packages, and sequence packets. There were described features and conducted an analysis of system use by a group of users. The basic algorithm of the given information system is described. The basic methods of solving the given problem are described. There was conducted a comparison of various techniques for analyzing large amounts of text, as well as organizing large volumes of text information. To work out user's Twitter posts, first, it was chosen combining intent analysis and psychosemantics as the most effective means of determining the specific features of the user, and secondly, they applied BM search algorithm, which proved to be the most effective of all the above algorithms and is not too difficult to implement. Also, there was conducted an analysis and selected the necessary means to solve the problem. There was chosen a platform (Electron) for building a web application and selected programming language to be used in the development of software solution.

There was carried out a description of the required software environment, in which the developed information system was developed, as well as provided a description of software tool implementation and results review. As a result of this work, there was achieved the set goal. There was created an information system that analyzes user's personal data (user's Tweets) and creates a psychological portrait of a person on the basis of five features: extraversion, integrity, gentleness, openness, and emotional stability. The software tool includes a user-friendly interface that is intuitive for even inexperienced PC users. This information system meets all current requirements, uses the latest web technologies, and allows users to analyze the text and form all the necessary conclusions based on them. 


\section{WORKS CITED}

Alizar, A. (2012). Sostavleniye modeli lichnosti po aktivnosti $v$ sotsial'noy seti. Retrieved from: https://xakep.ru/2012/04/26/58618/.

Bennett, J. (2012). Visualization Critique. Retrieved from: http://vizthinker.com/visualization-critique/.

Dzheffri, M. (2015). Recruiting 5.0: Psikhologicheskiye profili v sotsial'nykh setyakh. Retrieved from: http://www.hrportal.ru/blog/rekruting-50-psihologicheskie-profili-v-socialnyh-setyah.

Global Web Index. (2009). Social Web Involvement. Retrieved from: http://www.pamorama.net/wpcontent/uploads/2010/12/Global-Map-of-Social-Web-Involvement-Global-Web-Index-2009.pdf.

Kluemper, D.H., Rosen, P.A., \& Mossholder, K.W. (2012). Social Networking Websites, Personality Ratings, and the Organizational Context: More Than Meets the Eye? Journal of Applied Social Psychology, 42(5), p. 1143-1172.

Kosinski, M., Stillwell, D., \& Graepel T. (2013). Private traits and attributes are predictable from digital records of human behavior. Proceedings of the National Academy of Sciences. N. 110(15), 5802-5805.

Lovakov, A. (2013). Otsenka lichnosti po aktivnosti v sotsial'nykh setyakh ili Big Data prikhodyat v psikhologiyu. Retrieved from: http://psyresearchdigest.blogspot.com/2013_11_01_archive.html.

Prokhorov, A. (2015). Sotsial'nyye seti: psikhologiya, sotsiologiya, bíznes. Retrieved from: http://compress.ru/article. aspx?id=23890.

Schwartz, H. A., Eichstaedt, J.C., \& Kern M.L. (2013). Personality, Gender, and Age in the Language of Social Media: The Open-Vocabulary Approach. Plos One. 8(9). Retrieved from: http://journals.plos.org/plosone/article?id=10.1371/journal.pone.0073791

Shuotian, B., Tingshao, Z., \& Li, C. (2012). Big-Five Personality Prediction Based on User Behaviors at Social Network Sites. Retrieved from: http://arxiv.org/pdf/1204.4809v1.pdf, http://arxiv.org/abs/1204.4809.

Shuotian, B. (2012). List of computer science publications by Shuotian Bai. Retrieved from: http://dblp.unitrier.de/pers/hd/b/Bai:Shuotian.

Solov'yev, D. (2015). Potrebnosti i povedeniye lyudey v sotsial'nykh setyakh. Teoriya "laykov". Retrieved from: http://www.cossa.ru/234/13291/.

Vysotska, V., \& Chyrun L. (2013). Web Content Processing Method for Electronic Business Systems. International Journal of Computers \& Technology, 12(2), p. 3211-3220.

Vysotska, V., \& Chyrun L. (2014). Life Cycle Model of Commercial Content Processing in Electronic Commerce System. Computational Problems in Electrical Engineering. Founder and Publisher Lviv Polytechnic National University, 3(2), p. 118-122.

Vysotska, V., \& Chyrun L. (2014). Set-theoretic models and unified methods of information resources processing in e-business systems. Applied Computer Science journal, 10(3), pp. 5-22.

Vysotska, V., Chyrun L., Lytvyn, V., \& Dosyn, D. (2016). Methods based on ontologies for information resources processing : Monograph. LAP Lambert Academic Publishing. Saarbrucken, Germany.

Vysotska, V., Rishnyak, I., \& Chyrun L. (2007). Analysis and evaluation of risks in electronic commerce. CAD Systems in Microelectronics, CADSM '07, 9th International Conference. p. 332-333.

Received for publication: 14.01.2017

Revision received: $\quad 13.02 .2017$

Accepted for publication: 01.04.2017 


\section{How to cite this article?}

Style - APA Sixth Edition:

Chyrun, L., Andrunyk, V., \& Vysotska, V. (2017, July 15). Content analysis peculiarities of user internet activities for personality psychological state slice formation. (Z. Čekerevac, Ed.) MEST Journal, 5(2), 26-46. doi:10.12709/mest.05.05.02.04

Style - Chicago Sixteenth Edition:

Chyrun, Lyubomyr, Vasyl Andrunyk, and Victoria Vysotska. "Content analysis peculiarities of user internet activities for personality psychological state slice formation." Edited by Zoran Čekerevac. MEST Journal (MESTE) 5, no. 2 (July 2017): 26-46.

Style - GOST Name Sort:

Chyrun Lyubomyr, Andrunyk Vasyl and Vysotska Victoria Content analysis peculiarities of user internet activities for personality psychological state slice formation [Journal] // MEST Journal / ed. Čekerevac Zoran. - Toronto - Belgrade : MESTE, July 15, 2017. - 2 : Vol. 5. - pp. 26-46.

Style - Harvard Anglia:

Chyrun, L., Andrunyk, V. \& Vysotska, V., 2017. Content analysis peculiarities of user internet activities for personality psychological state slice formation. MEST Journal, 15 July, 5(2), pp. 26-46.

Style - ISO 690 Numerical Reference:

Content analysis peculiarities of user internet activities for personality psychological state slice formation. Chyrun, Lyubomyr, Andrunyk, Vasyl and Vysotska, Victoria. [ed.] Zoran Čekerevac. 2, Toronto - Belgrade : MESTE, July 15, 2017, MEST Journal, Vol. 5, pp. 26-46. 